\title{
Assessment of Effective Communication in International Schools in Developing Countries Based on the Berlo's SMCR Model
}

\author{
Christabel Chisha Muyanga1, Jackson Phiri² \\ ${ }^{1}$ Graduate School of Business, University of Zambia, Lusaka, Zambia \\ ${ }^{2}$ Department of Computer Sciences, School of Natural Sciences, Lusaka, Zambia \\ Email: cmuyanga14@gmail.com, jackson.phiri@cs.unza.zm
}

How to cite this paper: Muyanga, C. C., \& Phiri, J. (2021). Assessment of Effective Communication in International Schools in Developing Countries Based on the Berlo's SMCR Model. Open Journal of Business and Management, 9, 448-459.

https://doi.org/10.4236/ojbm.2021.91024

Received: December 7, 2020

Accepted: January 26, 2021

Published: January 29, 2021

Copyright $\odot 2021$ by author(s) and Scientific Research Publishing Inc. This work is licensed under the Creative Commons Attribution International License (CC BY 4.0).

http://creativecommons.org/licenses/by/4.0/

\begin{abstract}
Communication is important in an organization because it enables the organization to give information to both the internal and external public. Communication by leaders in schools enables them to communicate about the goals and vision of the school. It also allows them to give instructions to staff members. When communication is effective in a school, people are able to understand what is expected of them. The purpose of this study was to assess effective communication in International Schools in Lusaka based on Berlo's SMCR Model. The study was conducted at International School of Lusaka and Lusaka International Community School. The study utilized a quantitative paradigm. Questionnaires were used as a research instrument for collecting data from the Principals, Heads of Departments, Teachers and Support Staff who were purposively selected from a sample size of $135 \mathrm{em}$ ployees. The questionnaires were distributed to 110 people and 83 questionnaires were returned. The data collected using the questionnaire was analyzed using descriptive analysis and inferential statistics (Pearson Correlation Coefficient). Pearson Correlation Coefficient was used to determine the relationships between the variables. Two hypotheses were accepted as they showed a statistically significant relationship between the variables of which both had a $p$-value of 0.001 which is less than 0.005 .
\end{abstract}

\section{Keywords}

Communication, Effective Communication, Leader, International School, Berlo's SMCR Model 


\section{Introduction}

Communication is an important aspect in an organization. It is a means to bring about change. Effective communication has always been and still is an important aspect of human daily living (Fashiku, 2017). Effective communication is a primary function for all successful organizations, whether at initial start-ups, growing or in international companies (Yusuf et al., 2014). In any organization, communication is a necessity for coordinating most activities, and this is especially true in educational institutions (Ibrahim \& Mahmoud, 2003). Leaders in schools regularly communicate with teachers and support staff on different issues which affect the running of a school. Witherspoon (1997) claims, "Leadership exists only through communication. Leaders are increasingly important as creators of culture, decision makers, and change agents. These roles require the use of communication to develop shared meanings, search and use information effectively, and create and communicate visions to enhance an organization's future and guide it through eras of change".

There are different approaches to communication that Leaders take; communication is done face-to-face, meetings, memorandum, through email and newsletter. Leaders identify ways to communicate with the teachers or support staff depending on the type of communication.

There are things that leaders may consider when coming up with a message such as content of the message, the purpose of the message and who the message is targeting. The message may be for teachers only or support staff only therefore, the encoding of the message will be done to suit a particular group.

Communication in an organization can build relationships. The ability to communicate enables people to form and maintain personal relationships. These relationships help to create understanding with each other (Mumba \& Phiri, 2019).

The assessment of communication done in schools is very important because it gives the Leaders an insight to determine if the message has been understood or not. It will also help Leaders change strategies of communication if the current channels are not working.

\section{Literature Review}

Communication has been widely accepted by scholars and academies as the life hood of an organization because communication is needed for exchanging information, exchanging opinions, making plans and proposals, reaching agreement, executing decisions, sending and fulfilling orders and conducting sales (Shounubi \& Akintaro, 2016). Communication by school leaders is important as it allows the leaders to communicate instructions and clarify where instructions are not clear. Skillful communication has been broadly accepted as an important leadership attribute across disciplines (Dawn \& Tyler, 2016).

\subsection{Communication by School Leadership}

It is important that school leaders communicate clear instructions to teachers 
and support staff in order for them to carry out their duties. Teachers and support staff must be able to understand the message and when they are not clear they should ask questions. Poor communication by Leaders can lead to low morale by employees.

A study by Reyes \& Hoyle (1992) examined teachers' satisfaction with their principals' communication, feedback, and teachers' perceived adequacy of their principals' instructions in relation to specific teacher demographic variables found that teachers' ages were related to their communication satisfaction toward the principal. Meaning that, as the ages of the teachers increased, their communication satisfaction tended to increase. This was true for both male and female teachers. Correspondingly, as years of teaching experience increased, communication satisfaction also increased. For male teachers only, the data suggested that increasing their education negatively impacted their communication satisfaction.

Communication in schools by leaders is usually done in order to communicate daily tasks and duties. Principals communicate to teachers in order to ensure that the curriculum and syllabus of the school are followed. In a study by Ärlestig (2007) on the Principals' communication inside schools: A contribution to school improvement? The study found that communication within this school merely transmitted the information necessary for conducting daily work, which resulted in predictable behaviors, rather than stimulating learning and encouraging challenging dialogue about significant pedagogical and school improvement issues.

Communication is important in building trust and good relationships between leaders and teachers. A study by Dawn \& Tyler (2016) on Communication behaviors of principals at high performing Title I elementary schools in Virginia: School leaders, communication, and transformative efforts found that communication skills are necessary for building trust between school principals and teachers, with trusting relationships vital for leading teachers toward effective instruction. More structured leadership training is essential in the area of communication skills in preparing school leaders and is most effective at the school division level. When Leaders have training in communication skills they are able to communicate well with teachers and other members of staff.

A study on teacher perception of school principal interpersonal communication style: a qualitative study of a Turkish primary school used a qualitative research method which focused on teachers' views on communication styles of the school principal in a Turkish primary school by Sezgin (2016) found that communication within the school perceived by the interviews teachers was inefficient. The findings from the study pointed out that developing an interaction between the principal and teachers can allow open two-way communication. In order for communication to be effective, there is a need to have a two-way communication system. When a person is not clear about the message they are able to ask for a clarification. 
Effective communication by school leaders can lead to an increase of morale and job satisfaction. A study by Nwosu (2017) on principals' communication strategies and teachers' job performance in public secondary schools in Ikenne Local Government Area of Ogun State found that assessing teacher performance in an academic institution is as important as assessing learning in pupils and students; and that teachers' job performance to a large extent depends on factors like the principal communication strategies and resources. The population was the teachers in public secondary schools in Ikenne Local Government Area of Ogun State. A total number of 200 respondents were used in the survey. The tool used for data collection was a questionnaire.

\subsection{Berlo’s SMCR Model}

The Berlo's Model of Communication has four elements which are the Source, Message, Channel and Receiver (SMCR). Each element has five components as shown in Figure 1. The components of the Source are:

Communication skills-In order for the source to communicate effectively he/she needs to have good communication skills. Communication skills should include listening, speaking, reading and writing.

Attitude-The source needs to have a good attitude in order to communicate effectively. A person may be a good speaker but has a bad attitude towards the receiver therefore; the message cannot be communicated to the receiver.

Knowledge-It is an important aspect of communication. The source needs to be knowledgeable about the information that it wants to send.

Social Systems-Communication takes place in society where there are different people with different beliefs and values. The source needs to be aware of the culture, religion, belief and values of the receiver.

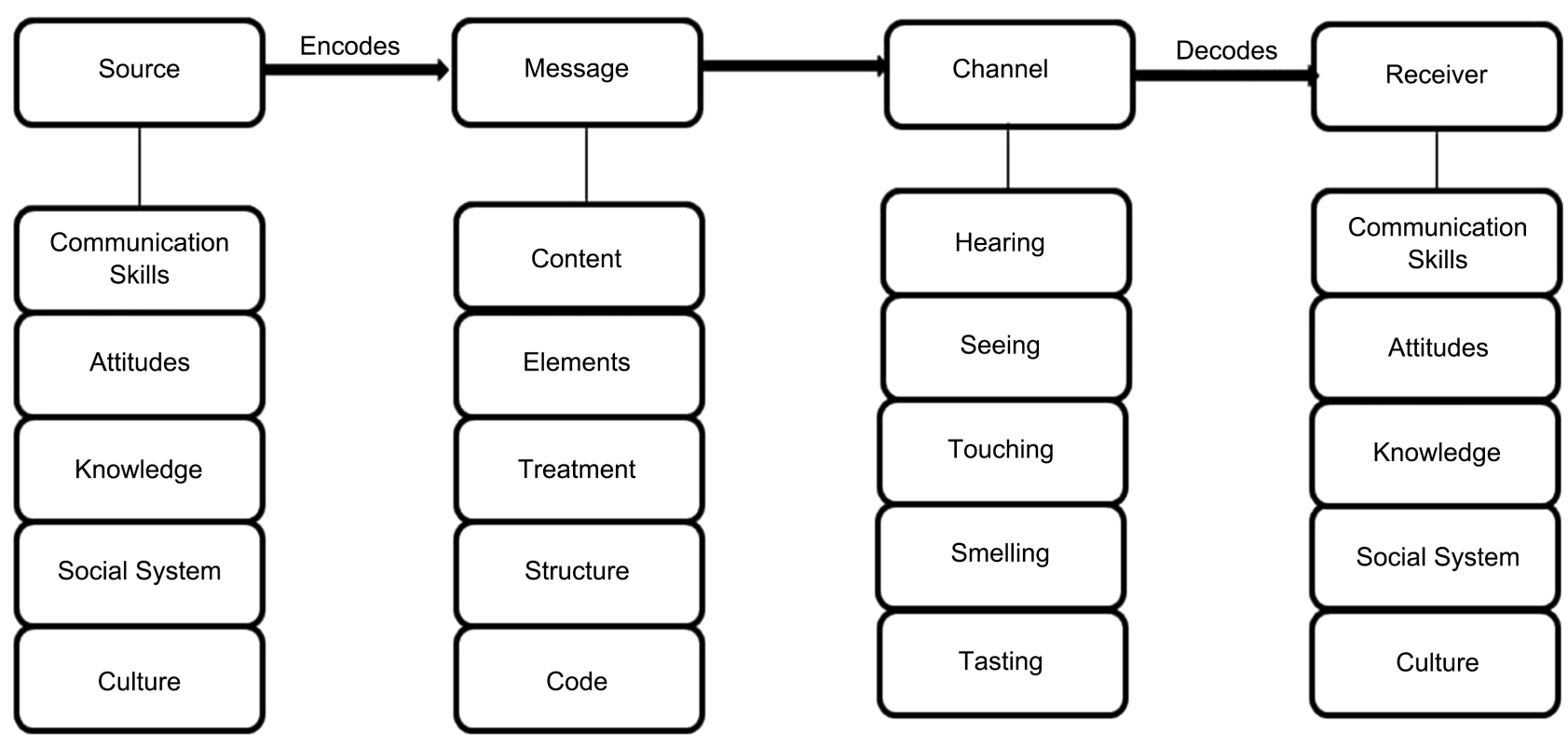

Figure 1. Berlo's SMCR Model (1960). 
Culture-the model also takes into consideration culture. Leonard et al. (2011) affirms culture and communication are inseparable because culture not only dictates who talks with whom, about what, and how the communication proceeds, it also helps to determine how people encode messages, the meanings they have for messages, and the conditions and circumstances under which various messages may or may not be sent, notices, or interpreted.

The components of the Message are; content, elements, treatment, structure and code. The components of the channel are; hearing, seeing, touching, smelling and tasting. The components of the receiver are similar to those of the source which are communication skills, attitude, knowledge, social systems and culture.

The Berlo's Model was used in the study to assess effective communication in International Schools in Lusaka, Zambia.

\section{Research Methodology}

The study employed quantitative survey design. Quantitative research is specific in its surveying and experimentation, as it builds upon existing theories (Leedy \& Ormrod, 2001). The researcher used quantitative research in order to respond to relationship questions between the variables. The study was carried out in Lusaka, Zambia and it targeted International Schools in Lusaka which offer international curriculum. The target population consisted of Principals, Heads of Department, Teachers and Support Staff. Target population is a group or category of human beings, animals and objects which have one or more characteristics in common and have been selected as a focus of the study (Mulusa, 1998).

A sample was drawn from the population which was used in the study. Best \& Khan (2006) assert a sample is a small proportion of a population selected for observation and analysis, the characteristics of which can enable the researcher to make certain inferences about the population from which sample was drawn. Purposive sampling was used to ensure that all departments were included in the sample. In purposive sampling, the researcher selects sampling units based on his or her judgement of what units will facilitate an investigation (Adler \& Clark, 2008). The sample size was determined by using the formula

$$
\begin{gathered}
\mathrm{n}=\mathrm{N} / 1+\mathrm{N}(\mathrm{e})^{2} \\
\mathrm{n}=135 / 1+135 \times 0.05^{2} \\
\mathrm{n}=100.934 \\
\mathrm{n}=101
\end{gathered}
$$

Equation (1) was used to determine the sample size, where $\mathrm{n}$ is the sample size, $\mathrm{N}$ is the population and $\mathrm{e}$ is the margin of error. The population had a total of 135 eligible participants and the error of margin was 5\%. The questionnaires were distributed to the respondents and only 83 questionnaires were returned.

\section{Data Collection and Analysis}

The study used a questionnaire to collect data from the respondents. The ques- 
tionnaire was adapted from the Berlo's SMCR Model. The components of the source, message, channel and receiver were used to come up with questions. The reason why the researcher used a questionnaire over other research instruments was so that suitable information was collected. The use of questionnaires is considered to be a good goal-attaining method to collect large quantities of data from respondents, on condition that they are well-designed and disseminated (Cameron \& Price, 2009). The questionnaire was also used because it is free of interview bias.

The questionnaire comprised 3 sections. The first section was demographic questions; the second were questions on the components of the source, message, channel and receiver of which a Likert scale was used for the variable under study. A 5 -point Likert scale ( $1=$ strongly disagree, $2=$ disagree, $3=$ neutral, $4=$ agree, $5=$ strongly agree) was used. The third section had questions about the channels of communication which also used a 5-point Likert scale.

The research addressed the following hypotheses:

$\mathrm{H}_{1}$ : There is a relationship between communication skills of the source and content of the message.

$\mathrm{H}_{2}$ : There is a relationship between content of the message and hearing.

$\mathrm{H}_{3}$ : There is a relationship between hearing and communication skills of the receiver.

The data was analyzed by using the statistical package for social sciences (SPSS) version 20. The analysis of data started with editing and inspecting of data pieces in order to identify any wrongly answered or not responded items. Data was analyzed by the use of frequencies, percentages and Pearson's correlation.

\section{Results and Discussion}

This section looked at the findings of research based on Berlo's SCMR Model. Data was analyzed using descriptive analysis and Pearson correlation coefficient was used to determine the relationship between the variables.

\subsection{Basic Statistical Analysis}

Out of the 110 questionnaires that were distributed 83 questionnaires were returned therefore, the response rate stood at $73 \%$. Two International schools in Lusaka took part in the survey. The majority of the respondents were female (51\%) compared to the males (49\%) as shown in Figure 2.

The majority of the respondents were Zambian (59\%), followed by British (12\%), Other Nationalities (11\%), Indian (7\%), American (6\%) and South Africa (5\%) as highlighted in Figure 3. Figure 4 shows that majority of the respondents were teachers at $47 \%$, support staff were $34 \%$, Head of Department were $17 \%$ and Principals were 2\%.

\subsubsection{Reliability and Validity}

A reliability test was done in order to measure internal consistency of the items 
of the questionnaire. Rovai et al. (2014) recommend measuring internal consistency and reliability using Cronbach's Alpha. Therefore, Cronbach's Alpha was used to determine if the questions in Likert scale for the survey were reliable. Reliability tests resulting in alpha of 0.70 are generally accepted as having high reliability (Rovai et al., 2014).

Table 1 below shows the results of the Cronbach Alpha test with all the items equal or greater than 0.70 .

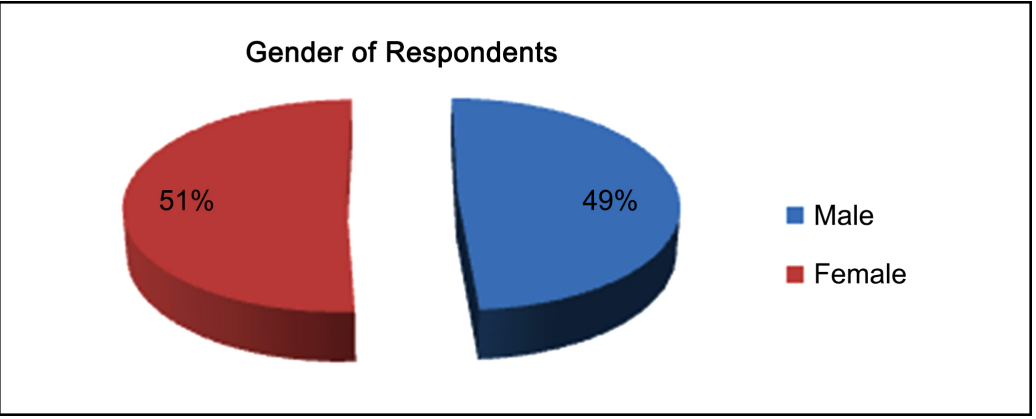

Figure 2. Gender of respondents.

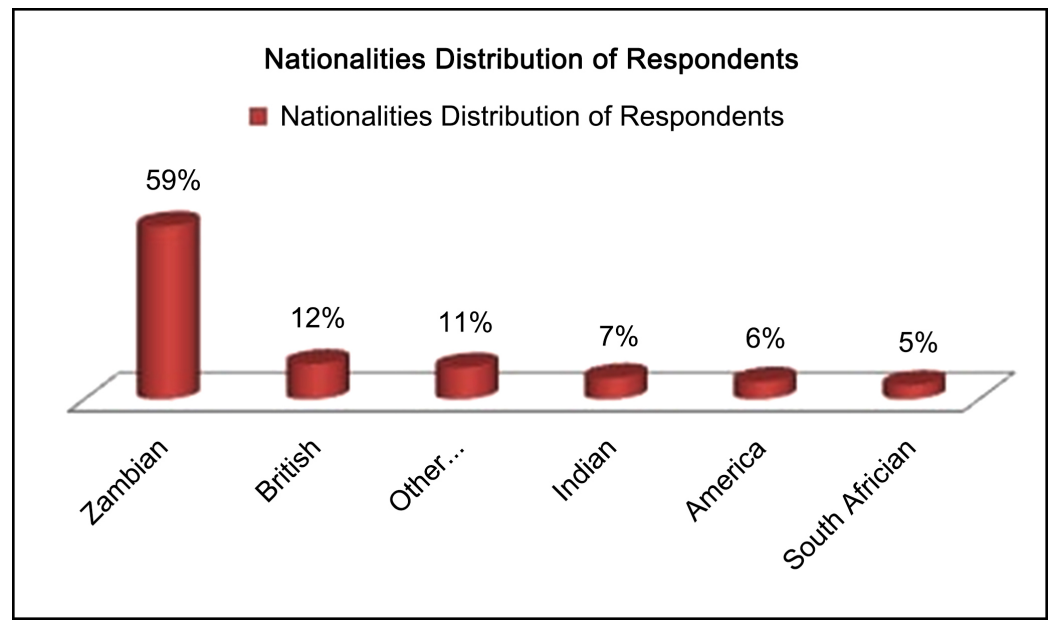

Figure 3. Nationalities distribution of respondents.

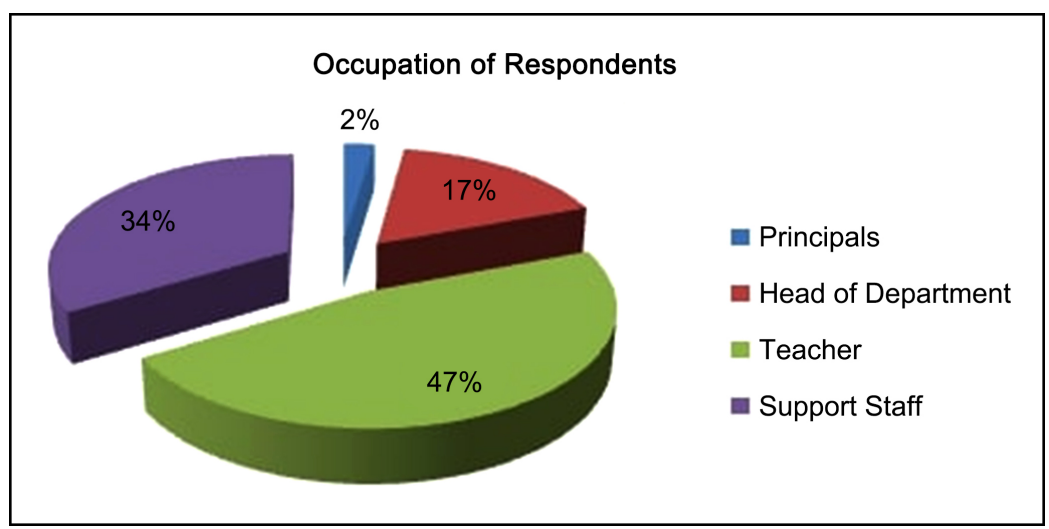

Figure 4. Occupation of respondents. 
Table 1. Cronbach's Alpa per construct.

\begin{tabular}{ccc}
\hline & \multicolumn{2}{c}{ Reliability Statistics } \\
\cline { 2 - 3 } Construct & Cronbach's Alpha & N of Items \\
\hline Source & 0.78 & 5 \\
Content & 0.72 & 5 \\
Message & 0.70 & 5 \\
Receiver & 0.75 & 5 \\
\hline
\end{tabular}

Validity is to measure what is intended to be measured (Field, 2005). In order for the researcher to ensure that the study was going to measure what was intended to be measured the research used content validity. Taherdoost (2016) content validity involves evaluation of a new survey instrument in order to ensure that it includes all the items that are essential and eliminates undesirable items to a particular construct domain. Content validity was used in the study and a panel of three experts reviewed the questionnaire to ensure that the questions were relevant to the study.

\subsubsection{Testing Hypotheses Correlations}

Three hypotheses were tested using Pearson correlation. A Pearson correlation was utilized to determine whether the variables were significantly linearly related. The value of the coefficient ranges from -1 to +1 where the absolute value of the Pearson correlation coefficient signifies the strength of the linear relationship (Norusis, 2009).

Thus, a correlation analysis provided information on the strength and direction of the relationship between the variables. Table 2 shows the results of whether there is a relationship between communication skills of the source and content of the message. A Pearson correlation coefficient of 0.001 was found which is statistically significant if the (sig. 2 -tailed) $<0.05$. Therefore, the null hypothesis was rejected as there was a statistical significant relationship between the two variables.

A Pearson correlation coefficient was done to determine if there was a relationship between content of the message and hearing. It was found that content of the message and hearing have a significant relationship with a $p$-value (sig. 2 tailed) 0.001 as shown in Table 3 . The null hypothesis was rejected as there was a statistically significant relationship between the content of the message and hearing.

Table 4 shows a Pearson correlation coefficient which was done in order to determine the relationship between hearing and communication skills of the receiver. A Pearson's $r$ analysis revealed a weak correlation, $r=0.196$. The significant level was 0.076 which is greater than 0.005 . Therefore, the null hypothesis was accepted as there is no statistically significant relationship between hearing 
and communication skills of the receiver.

The analysis carried out and results of the hypothesis test are tabulated in $\mathrm{Ta}$ ble 5 .

Table 2. Communication skills/content of message correlation.

\begin{tabular}{cccc}
\hline & Correlations & $\begin{array}{c}\text { Communication skills } \\
\text { (reading, listening } \\
\text { and speaking) }\end{array}$ & $\begin{array}{c}\text { Content (package } \\
\text { or meaning of } \\
\text { information) }\end{array}$ \\
\hline $\begin{array}{c}\text { Communication skills } \\
\text { (reading, listening } \\
\text { and speaking) }\end{array}$ & Pearson Correlation & 1 & $0.366^{* *}$ \\
\hline $\begin{array}{c}\text { Sontent (package } \\
\text { or meaning of } \\
\text { information) }\end{array}$ & Pearon Correlation & 83 & 0.001 \\
\hline & Sig. (2-tail) & $0.366^{* *}$ & 1 \\
\hline
\end{tabular}

${ }^{\star *}$ Correlation is significant at the 0.01 level (2-tailed).

Table 3. Content/hearing correlation.

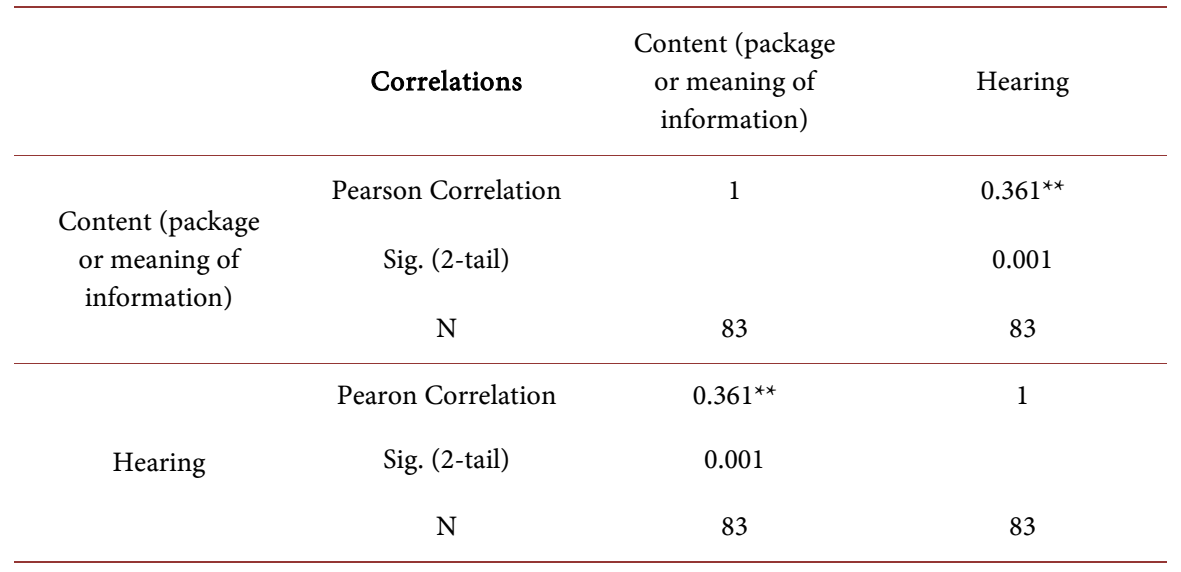

${ }^{\star *}$ Correlation is significant at the 0.01 level (2-tailed).

Table 4. Content/hearing correlation.

\begin{tabular}{cccc}
\hline & Correlations & Hearing & $\begin{array}{c}\text { Communication skills } \\
\text { of receiver }\end{array}$ \\
& Pearson Correlation & 1 & 0.196 \\
Hearing & Sig. (2-tail) & & 0.076 \\
& $\mathrm{~N}$ & 83 & 83 \\
\hline $\begin{array}{c}\text { Communication skills } \\
\text { of receiver }\end{array}$ & Pearon Correlation & 0.196 & 1 \\
& $\mathrm{~N}$ & 0.076 & 83 \\
\hline
\end{tabular}


Table 5. Summary of hypothese results.

\begin{tabular}{ccc}
\hline No. of Hypothesis & \multicolumn{1}{c}{ Hypothesis statement } & Results \\
\hline $\mathrm{H}_{1}$ & $\begin{array}{c}\text { There is a relationship between comminication } \\
\text { skills of the source and content of the message } \\
\text { There is a relationship between content of the } \\
\text { message and hearing }\end{array}$ & Accepted \\
$\mathrm{H}_{2}$ & $\begin{array}{c}\text { There is a relationship between hearing and } \\
\text { communication skills of the receiver }\end{array}$ & Accepted \\
\hline
\end{tabular}

\section{Conclusion}

The correlation results showed that there was a relationship between communication skills of the source and content of the message. There was also a relationship between the content of the message and hearing. However, there was no relationship between hearing and communication skills of the receiver; therefore, the null hypothesis was accepted.

The data collected with a questionnaire revealed that some factors that affect effective communication in International Schools in Lusaka are lack of knowledge by the source. The source may not have enough knowledge about the information that they want to transmit hence the message will be misunderstood.

\section{Limitations}

When conducting a research there are usually limitations. This is because no one study is able to address all aspects of a problem. The limitation of the study was that the study only used quantitative methods in collecting data. Hence the study did not capture the feeling, attitudes and the behaviour of the people. It also did not give the researcher much opportunity to ask questions. The Researcher could have used both qualitative and quantitative methods for collecting data so that where the quantitative method fails to get information then qualitative method can collect the data. Including qualitative methods could also allow the researcher to ask in-depth questions to the respondents. The other limitation was that the study only focused on two International Schools in Lusaka and omitted public schools in Zambia which would have given a broader view of effective communication in school.

\section{Recommendations}

Effective communication is very important for the successful sending of the message to employees. School leaders can successfully send messages if they improve their communication skills. In communication skills, school leaders should be able to listen attentively to what the subordinates are saying. Speech is also an essential aspect of communication. Leadership in International Schools should speak clearly and use language that is acceptable to people. They should also have a reading culture in order to acquire knowledge. 
Leaders in International Schools must be trained in communication skills and management because they communicate with both teachers and support staff who work in administration with different cultural backgrounds.

Understanding the various aspects of employees will enable the leaders to communicate effectively. Leaders in International schools should take into consideration their employees beliefs, values and culture. The study discovered that most Leaders in International Schools are expatriates and the majority of support staff are Zambians therefore, Leaders must take an interest in learning about the Zambian culture because culture plays an important role in effective communication.

Since the study was only limited to International Schools it is recommended that further study should be done on effective communications in all schools including public schools. It is also recommended that both quantitative and qualitative research should be done in order to get more information on effective communication in schools so that the information obtained is generalized.

\section{Acknowledgements}

The author would like to acknowledge the valuable contribution from the participants of the schools that took part in the survey and the school management for allowing the author to collect data.

\section{Conflicts of Interest}

The authors declare no conflicts of interest regarding the publication of this paper.

\section{References}

Adler, E. S., \& Clark, R. (2008). How It's Done: An Invitation to Social Research. London: Thomson Wadsworth.

Ärlestig, H. (2007). Principals' Communication Inside Schools: A Contribution to School Improvement? The Educational Form, 71, 262-667.

https://doi.org/10.1080/00131720709335010

Best, J. W., \& Kahn, J. (2006). Research in Education. New Delhi: Prentice Hall of India, Pvt, Ltd.

Cameron, S., \& Price, D. (2009). Business Research Methods: A Practical Approach. London: CIPD.

Dawn, E., \& Tyler, E. D. (2016). Communication Behaviors of Principals at High Performing Title I Elementary Schools in Virginia: School Leaders, Communication, and Transformative Efforts. Creighton Journal of Interdisciplinary Leadership, 2, 2-16. https://doi.org/10.17062/cjil.v2i2.51

Fashiku, C. O. (2017). Effective Communication: Any Role in Classroom Teaching-Learning Process in Nigerian Schools. Bulgarian Journal of Science \& Education Policy (BJSEP), 11, 171-187.

Field, A. P. (2005). Discovering Statistics Using SPSS. London: Sage Publications Inc.

Ibrahim, A., \& Mahmoud, S. (2003). Principals' Communication Styles and School Per- 
formance in Al Ain Government Schools, UAE. International Journal of Research Studies in Education, 6, 29-46. https://doi.org/10.5861/ijrse.2016.1421

Leedy, P., \& Ormrod, J. (2001). Practical Research: Planning and Design (7th ed.). Upper Saddle River, NJ: Merrill Prentice Hall.

Leonard, K. M., Van Scotter, J. R., Pakdil, F., Chamseddine, N. J., Esatoglu, E., Gumus, M., Koyuncu, M., Wu, L. L., Mockaitis, A. I., Salciuviene, L., Oktem, M. K., Surkiene, G., \& Tsai, F. (2011). Examining Media Effectiveness across Cultures and National Borders: A Review and Multilevel Framework. International Journal of Cross Cultural Management, 11, 83-103. https://doi.org/10.1177/1470595810389790

Mulusa, T. (1998). Evaluating Education and Community Development Programmes. Nairobi: CADE, University of Nairobi.

Mumba, J., \& Phiri, J. (2019). Bridging Departmental Communication Gaps in Quasi-Institutions: A Case Study of ZESCO Limited. Open Journal of Business and Management, 7, 2009-2019. https://doi.org/10.4236/ojbm.2019.74138

Norusis, M. J. (2009). SPSS 17.0 Advanced Statistical Procedures Companion. Upper Saddle River, NJ: Prentice Hall.

Nwosu, J. C. (2017). Principals' Communication Strategies and Teachers' Job Performance in Public Secondary Schools in Ikenne Local Government Area of Ogun State. International Journal of Education, Learning and Development, 5, 1-12.

Reyes, P., \& Hoyle, D. (1992). Teachers' Satisfaction with Principals' Communication. Journal of Educational Research, 85, 163-168.

https://doi.org/10.1080/00220671.1992.9944433

Rovai, A., Baker, J., \& Ponton, M. (2014). Social Science Research Design and Statistics: A Practitioner's Guide to Research Methods and IBM SPSS Analysis. Chesapeake, VA: Watertree Press LLC.

Sezgin, F. (2016). Teacher Perception of School Principal Interpersonal Communication Style: A Qualitative Study of Turkish Primary School. International Online Journal of Educational Sciences, 8, 10-19. https://doi.org/10.15345/iojes.2016.04.002

Shounubi, A. O., \& Akintaro, A. A. (2016). Effective Communication on Organizational Performance. The International Journal of Social Sciences and Humanities Invention, 3, 1904-1914.

Taherdoost, H. (2016). Validity and Reliability of the Research Instrument; How to Test the Validation of a Questionnaire/Survey in a Research. International Journal of Academic Research in Management, 5, 28-36. https://doi.org/10.2139/ssrn.3205040

Witherspoon, P. D. (1997). Communication Leadership-An Organisational Perspective. Boston, MA: Allyn and Bean.

Yusuf, B. M., Zulkifile, Z., Rashid, I. M., \& Kamil, S. (2014). A Study on Barriers of Cross-Cultural Communication in Electronic Based Companies. The International Journal of Social Sciences, 27, 187-196. 